\title{
Ground Rules in Team Projects: Findings from a Prototype System to Support Students
}

\author{
Janice Whatley \\ Salford Business School, University of Salford
}

J.E.Whatley@salford.ac.uk

\section{Executive Summary}

Student team project work in higher education is one of the best ways to develop team working skills at the same time as learning about the subject matter. As today's students require the freedom to learn at times and places that better match their lifestyles, there is a need for any support for team project work to be also available online. Team working requires that the task roles as well as the maintenance roles are taken into consideration, in that social interactions are just as important as carrying out the tasks of the project.

The literature indicates that groupware, whilst effective in supporting the task roles, provides limited support for the maintenance roles of team working in the work place. As groupware was not specifically designed for student team working, it provides limited support for maintenance roles in student team projects. Virtual learning environments similarly provide support for completing the task roles. Many researchers have found that students experience difficulties with their team project work that reduce the perceived benefits of working in a team. It is proposed that helping students to agree on ground rules at the start of a project will improve team cohesion.

This paper describes the implementation and evaluation of a prototype system to help students to agree on ground rules as they start their team projects. The system was tested with teams of students carrying out information systems team projects, using an interpretive case study research approach. In this case the teams had the additional problem of being composed of students from across three years of their undergraduate degree programmes, so they did not always have prior knowledge of each other's preferences. We were trying to establish how useful this software tool would be to these student teams, in starting their project work.

The findings showed that some of the student teams did find the ground rules function useful, but the team leaders were the ones who most appreciated its potential. The students may use the outputs in very different ways, but even just looking at the ground rules appeared to get team members thinking about their expectations for team working. Student teams do not often start by thinking about norms, but this study shows a positive benefit of encouraging teams to agree on ground rules at the start of their projects.

Material published as part of this publication, either on-line or in print, is copyrighted by the Informing Science Institute. Permission to make digital or paper copy of part or all of these works for personal or classroom use is granted without fee provided that the copies are not made or distributed for profit or commercial advantage AND that copies 1) bear this notice in full and 2) give the full citation on the first page. It is permissible to abstract these works so long as credit is given. To copy in all other cases or to republish or to post on a server or to redistribute to lists requires specific permission and payment of a fee. Contact Publisher@InformingScience.org to request redistribution permission.
Keywords: ground rules, student team project, information systems, case study

\section{Introduction}

In higher education a team project is one of the best learning activities for developing skills, such as team working and use of Computer Mediated Communication (CMC) tools (Mennin, 2007). Fur- 
ther, students are learning about team working at the same time as consolidating their learning about the subject matter by applying theories learned. Team working in organisations is fraught with difficulties, such as communication and conflict, and student team working is similarly beset with problems (Lehtinen, Hakkarainen, Lipponen, Rahikainen, \& Muukkonen, 2002; Ruel \& Bastiaans, 2003). But with limited experience of team working, students cannot always overcome these difficulties, and many student team projects fail to deliver satisfactory outcomes. In their study, Dunne and Rawlins (2000) recognised that a team project in higher education can provide a safe environment for learning about team working, although students do need to be provided with some guidance as they embark on team working (Hansen 2006; Prichard, Stratford, \& Bizo, 2006). Felder and Brent (1994) introduced cooperative learning to engineering students and concluded that the benefits to students outweighed the problems arising in their team working, but many academics remain to be convinced that team project work is a good learning activity.

Research has highlighted some of the difficulties students experience in their team working as organising meetings, team members not contributing, free-riding and coming to trust each other (Burdett 2003; Whatley, Staniford, Beer, \& Scown, 1999). The tutor can play a part in helping teams to overcome problems (Ruel \& Bastiaans, 2003), but as class sizes increase, tutors are becoming hard pressed to offer timely support (Cooper \& Heinze, 2003). Effective project management can generate team cohesion, and agreeing on ground rules at the start of a project is a part of effective project management (McAlister, 2006). Ground rules, also known as norms, are protocols for acceptable behaviour within a team and may comprise task related rules as well as social rules (Patterson, Carron, \& Loughead, 2005).

Employers are increasingly looking for graduates with well developed team working skills (Hordyk, 2007). Although many agree that team-working skills are important for undergraduate students to acquire, in preparation for working in business, successful teamwork is more difficult to achieve when students have fewer opportunities to meet face to face (Fellers, 1996). An unsatisfactory team working experience as a student can lead to a reluctance to join in teams in the workplace (Livingstone \& Lynch, 2000).

Lifestyles of campus-based students are changing, as they often work part time, have family commitments, and most students spend less time on campus. This can only make arranging meetings and getting to know their fellow team members more difficult. Campus based students are increasingly using online support for their learning as well as the traditional face to face support offered by tutors and peers.

In this paper we explore the suitability of online support to help students with their team project work and describe the implementation of a software system to help agreeing on ground rules for the team. The next section presents a review of the literature, used as a background to this research, which is followed by a description of the implemented support system and an evaluation of its impact upon the student teams in the trial. Finally, some conclusions are drawn and directions for future work are suggested.

\section{Team Working Literature}

In this section the literature on transferable team working skills for students, the importance of ground rules for developing trust and cohesion, and organisational team working are reviewed. The contribution of groupware and other computer mediated communication tools is evaluated, and limitations of current tools for teams working are identified.

In higher education, team projects, particularly in the computing and information systems disciplines, are a good way to promote team working in an experiential learning environment (Griffiths \& Partington, 1992). Co-operative working in a team includes collaborative elements, 
as well as interdependent and group processes; parts of the work may be accomplished individually, but each is held accountable for his or her tasks, when all tasks are brought together (Johnson, Johnson, \& Smith, 1991).

The transferable skills desirable for effective team working include: an appreciation of the factors contributing to group dynamics; recognising the relationships between individual, team, and task; participating in activities that build up trust; and appreciation of the stages a team develops through. Individual skills for co-located team working are well documented (e.g., Beranek, Zuser, \& Grechenig, 2005; Johnson \& Johnson, 1997). Typical of the guidance offered in higher education is:

- Exercise leadership skills, if necessary;

- Negotiate;

- Be assertive, to put over your points without aggression;

- Manage people and resources;

- Understand how others feel or might act (Canterbury 2003).

Many researchers have divided team working elements into two parts, such as the maintenance and task roles of Hartley (1997), work and basic assumption roles (Bion, 1961), task and socioemotional roles (Bales, 1970), product and process roles (Belbin, 2000; Brown, 2000; Johnson \& Johnson, 1997), or the three parts of task, maintenance, and process roles (Syer \& Connolly, 1996). These have in common the notion of interrelated roles necessary to achieve successful team working. Task roles include analysis, problem solving, decision-making, planning, and design or build. Maintenance roles are concerned with individuals' feelings and relationships between team members, continually working towards team development, i.e., the processes of team working. The maintenance roles play a part in preventing negative conflict from arising through polarising of individual desires and beliefs, which can inhibit performance of the team (Syer \& Connolly, 1996).

One of the accepted models of team processes is that coined by Tuckman (1965): Forming, Storming, Norming and Performing. This model reflects the stages that teams pass through as they work together over time. In the learning organisation or educational context, a further stage, Informing, is also important, because there is much to be gained by reflecting on the processes the teams have gone through in achieving their goals (Garratt, 1994). The storming stage may be composed of varying degrees of conflict between team members, but through negotiation and coming to a shared understanding, a trust develops at the norming stage, during which the real work begins.

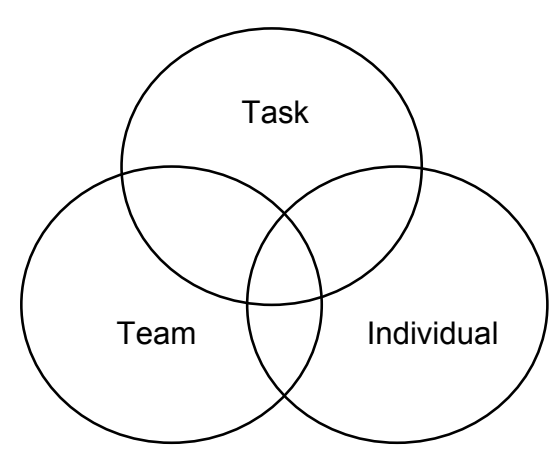

Figure 1 - Model of team, task and individual needs overlapping (Adair 1986) 
The literature suggests that team working revolves around three intertwined areas of team, individual, and task (Figure 1). Team working comprises task and maintenance roles, which overlap, and the literature suggests that having a common purpose and an equitable division of labour play a part in the task roles of a team project. The maintenance roles are affected by individuals' expectations of behaviour, how members adapt to the social situation of their work, methods of communication, and how conflict within the team is managed. Leadership is regarded as key to successful projects, whether a leader is formally appointed or informally emerges from within the team.

Evaluation of teams at work have provided some agreement about the factors that affect the success of a co-located team, i.e., a team that is able to work face to face, and Berge (1998) summarises the critical ones as:

- Goals - a clear mission for the team, with defined outcomes;

- Skills - the team needs to be composed of people with the required skills;

- Leadership - someone to motivate and keep an eye on the path to the goal;

- Roles - in addition to leaders, each team member has a role to play;

- Processes - planning, decision-making, problem solving and sharing;

- Interpersonal relations - generating a commitment to the goals without conflict arising;

- Accountability - maintaining standards of work, praising good work;

- Client involvement - the outcomes of team work need to be communicated to the client and other stakeholders.

Research points to an emphasis on the importance of developing positive group dynamics, through trust building and developing team cohesion (Golembiewski \& McConkie, 1975), the need for good communication, to deal with norms and expectations (Hartley, 1997), effective team leadership (Zaccaro, Rittman, \& Marks, 2002), and dealing with conflict (Brown, 2000). It is often the team leader or manager who is instrumental in encouraging good team dynamics (Ford \& Morice, 2003).

Groupware was designed to support the task oriented roles of team working, but there is limited support for the maintenance roles of team working, which tend to be problematical both on campus and in the workplace (Allison, McKechan, Ruddle, \& Michaelson, 2001; Edwards \& Clear, 2001). Also, groupware was designed for supporting dispersed teams of workers, rather than for use with students, so does not always provide adequate support to help them to recognise the issues relating to team working (Brereton et al., 1998).

The variety of CMC tools available to enhance communication, include email, forums, and document sharing, and these provide different levels of affordance to students, depending upon their motivation and their ability to use the tool (Conole \& Dyke, 2004). The affordance provided by tools may not be the same as those intended by the system's designers; technical affordance, educational affordance, and social affordance are all desirable properties of an educational information system designed to support team working (Conole \& Dyke, 2004). Many tools are based on individual use, rather than any attempt to support groups of learners (Lakkala, Lallimo, \& Hakkarainen, 2005), and there are few tools designed for supporting student team project working (Chapman, Ramondt, \& Smiley, 2005; Gatlin-Watts, Carson, Horton, Maxwell, \& Maltby, 2007).

Research in a telecommunications organisation showed that providing members of the team with information, training, and skills enhanced the common perceptions of their working environment, which led to developing common ground rules and performance measures, aiding improved "team wellness" (Groesbeck \& Van Aken, 2001). Ground rules are an expression of shared ex- 
pectations of membership, also known as norms and standards, representing the culture of the team, which contribute to the norming stage of a team.

Setting ground rules is important for agreeing how the team will operate (Aranda, Aranda, \& Conlon, 1998). Team members need to have a clear understanding of the ground rules adopted by the team, and communication of these rules is important at the initial stages of a project (Burdman, 1999). Hartley (1997) suggests that communication is often ad hoc unless ground rules are drawn up at the beginning. The importance of ground rules in collaborative knowledge sharing, managing personalities, and monitoring and maintaining teams was emphasised by other researchers (e. g., Bock, Kankanhalli, \& Sharma, 2006; Driskell, Goodwin, Salas, \& O'Shea, 2006; Groesbeck \& Van Aken, 2001).

In a study with students from five different higher education institutions, it was found that students rarely pay much attention to agreeing on ground rules before they embark on their team projects (Whatley et al., 1999). When the team project was completed without establishing ground rules at the beginning, this may have contributed to some of the problems that arose in these teams, which resulted in some projects not being completed satisfactorily or on time.

Trust or reliance is an important feature of work teams, based upon the socio-emotional level at which the team is working. A team based on mutual trust is cohesive and co-operative, whereas a non-trusting team is defensive (Golembiewski \& McConkie, 1975). Trust implies reliance on or confidence in some event, process, or person, reflecting an expectation about outcomes based on perceptions and life experiences. In team project work each member relies upon other members to perform particular tasks and to agreed deadlines, and failure to deliver reduces the levels of trust members will have in each other. Trust implies some risk in the expectation of gain, so at the early stages of the group life cycle members trust each other on the basis of little knowledge about others' experience and abilities, but if delegation of tasks and work is successful the group benefits considerably in performance at the task level towards the final product. In a study of trust within face-to-face teams, a possible relationship between trust in teams and setting ground rules was found (Bos, Olsen, Gergle, Olsen, \& Wright, 2002). Knowing about each other's capabilities and preferences can be a factor in developing trust, for instance, contributing to a "shared language", understanding, or shared knowledge base (Powell, Piccoli, \& Ives, 2004). Knowing facts about someone is not necessarily the same as knowing someone, but it may play a large part in moving individuals in the team from:

\section{Us/Them to $\mathrm{You} / \mathrm{I}$ and to $\mathrm{We}$,}

which is indicative of members developing good team dynamics.

Newell, David, and Chanel, (2007) proposed three types of trust - companion trust, commitment trust, and competency trust - and found in their studies that low levels of companion trust and commitment trust led to difficulties finding help and coordinating the team working activity. A common understanding, through agreed upon ground rules, can promote a trusting environment, encourage commitment and freedom to express views and ideas, and promote concentration on the tasks to be completed.

Norms and ground rules are concerned with the ways in which the team members work together and react to each other. A team relies on its members to perform what is expected of each member and to agreed deadlines (Driskell et al., 2006). When team members fail to perform to the expectations of other team members, trust levels start to fall, and cohesion, or sticking together, reduces. Agreeing on relevant ground rules for the team and adhering to them is said to ensure that trust levels are maintained, with improved cohesion (Bos et al., 2002).

Learning together, supported by technology, requires tools specifically designed for the environment of an experiential learning activity, such as team projects. These tools should help team 
members to communicate data and information between each other, to promote shared understanding, trust, and cohesion, and to be always available. In the next section the implementation and evaluation of a prototype system, which automates the process of team members agreeing ground rules for team projects, is described.

\section{Implementing and Using the Ground Rules System}

An interpretive case study approach was adopted for this research, so that the system developed could be tested with the particular case, in order to seek valuable information on the part played by ground rules in a team's processes. Although the results may not be generalisable to other forms of student team project work, the findings will provide some insight into team working processes.

The case study chosen for this research is a multi-year team project scheme in a higher education institution in the UK. The projects play an integral part in two undergraduate degree programmes: Business Information Systems and Business Information Technology. These are three year long programmes with an optional industrial placement year (Cooper \& Heinze, 2003). Students from the first, second, and final years of their degree are formed into teams of between 10 and 15 members, and a team leader and deputy are appointed by the tutor.

Each team works on a different real life information technology project developed in consultation with a client organisation. The clients range from local charitable organisations, local branches of large multi national companies, and community projects, to departments internal to the university, such as administrative divisions. The projects these clients provide represent real life problems to be solved, which is as close to working in an organisation as can be achieved on campus. Projects range in scope from developing database systems or developing web pages to feasibility studies of proposed systems or research into appropriate systems to solve organisational problems.

The Blackboard VLE is used to support the team project module, providing team areas for file exchange and a repository for the team project related documentation. Space on a local file server is also provided for each team, so that they can try out possible solutions for clients' system problems. A prototype student team project support system was developed and tried with the teams of this case study, and the link to this system was provided in Blackboard. One of the functions that this system provides for student teams is help to establish individual members' preferences for ground rules and to suggest adoption of rules that the majority of team members agree are important for the team.

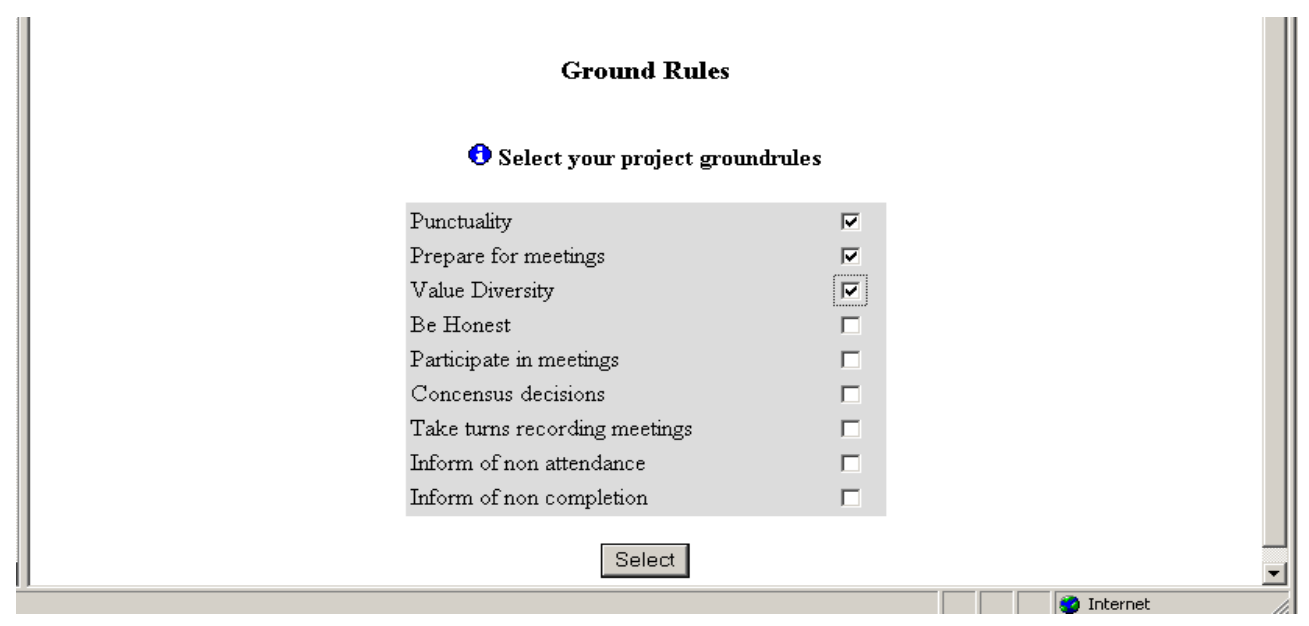

Figure 2: Screen display for team members to select preferences for ground rules 
The system works by asking each team member to select from a list of suggested ground rules those rules they think are important to the team (Figure 2). The system stores the responses from each team member and returns a list of suggested ground rules, based on those that more than half of the team members selected (Figure 3). The team leader can use these suggestions as a basis for discussion with the team members to agree on a final list of ground rules for the team to adopt for their project.

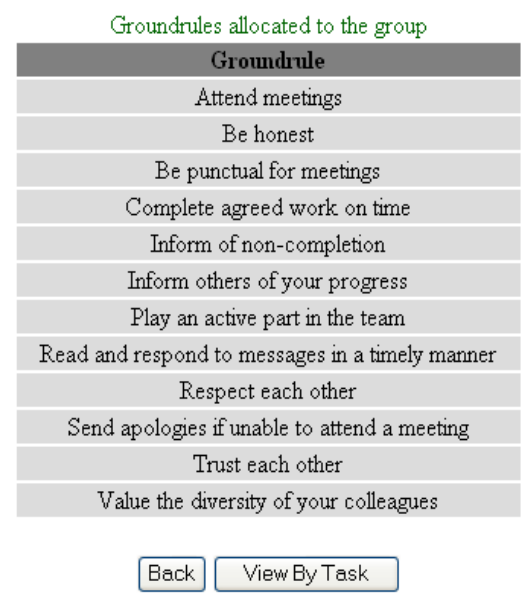

Figure 3: Screen display for suggested allocation of ground rules for the team

The system was made available to all of the teams working on projects, forming this case study, over a period of two academic years. The teams were introduced to the system in the first week, and asked to use it in the following two weeks. Not all of the teams chose to use the system, so after this time feedback was collected from the students who did use the system, through questionnaires completed by team members, interviews with team leaders, and a focus group to which all students were invited. This wide ranging qualitative feedback was analysed by sorting individual comments into themes, in order to ascertain the impact of this sort of support on various aspects of the student team working processes. It was hoped that these students would be a good test of whether agreeing on ground rules would help the team members to get to know each other better at the start of the project.

\section{Findings from the Students}

From the literature it is evident that the use of norms or ground rules is a factor in the maintenance roles of team projects and a precursor of good team cohesion. The ground rules function served to provide a means of ascertaining individuals' perceptions of the importance of each suggested ground rule and of automating a process for finding a consensus for agreeing on appropriate rules for the team to adopt.

In the first year of the trial only one of the six teams actually used the agreeing ground rules function. Although functionality is provided, users may not choose to use it or may not use it in the way it was anticipated by the designer, for example as experienced by Lakkala et al. (2005), whose findings were that teachers found it difficult to predict their students' use of technology tools. All six of the teams the following year used the function to input their preferences for ground rules, because this time the function was specifically pointed out to the team leaders. Overall almost half of the students said that the agreeing ground rules function was useful to 
them. But the teams did not necessarily use the output in ways anticipated by the designer, and analysis of feedback on their actual use of the system gave rise to some interesting findings.

This section identifies feedback concerned with the ways in which the project teams of this case study recognised the need for ground rules, their use of the system's output suggestions of ground rules, and the impact this function had on their team projects. The next section is divided into three parts: the use made of the suggested list of ground rules, the effect upon trust within the teams, and the affordance of the tool. Most of the quotes included were from team leaders, but other comments from members of the teams are indicated by the abbreviation TM.

\section{How Students Used the System}

The team leader had the discretion to use the output in any way he/she felt suitable for the particular team, whether the output was used formally or informally:

"Just looking rather than formal"

"Common sense, don't need rules. Good to highlight to team at start. Make it into a Contract”

Even though students may feel that ground rules are common sense, establishing some working rules at the beginning may help to engender team cohesion. Appelbaum and Shapiro (1998) suggest that handling conflict includes diagnosis and planning for overcoming it, including agreements on behaviour, which constitutes ground rules. The idea of a written contract that all team members sign had been used by many of the teams in this case study in the past, and in this research several team leaders used the output from the system to formulate a contract to use in practice:

"Ground rules used to establish a Contract"

"I did make a team contract which includes some of the ground rules from the system"

It is difficult to determine whether seeing a list of ground rules, and seeing the output list of those rules the majority of members agreed with, actually contributed to a feeling of team cohesion:

"...by looking at the ground rules, the team had a better understanding of team working, and I based the contract on them..."

"Team contract helped performance, like in outside world. Know the rules"

- Complete agreed work on time

- Inform of non-completion

- Read and respond to messages within agreed time

- Inform others of progress

- Respect consensus decisions

- Value diversity

- Be honest

- Play an active part in the team

- Trust each other

- Respect each other

- Attend meetings that have been arranged

- Prepare for meetings

- Be punctual for meetings

- Send apologies if unable to attend

Figure 4: List of ground rules included in the system 
The full list of ground rules included in the system are given in Figure 4, but team leaders were able to omit some rules if they were felt not to be appropriate for their particular team project.

The ground rules were considered by most respondents to be a comprehensive list of possible rules. However, it was noted by the module tutor that in the past these students had rarely considered agreeing on ground rules at the beginning of their projects. The ground rules function did change the ways in which some teams worked, for example:

"... a big list but they are effective"

"It did use it, but not how I thought I would"

"Good to highlight to team at start, made them think about expectations"

Individuals may interpret rules differently, so a common understanding is important, which may contribute to improved team performance. The list of ground rules presented were summarised by one team leader as a contributing factor for a successful project:

"...getting people's opinions, one of the success factors of the project"

There was a general feeling that the list of ground rules presented by the system and getting the opinion of all team members on their importance was useful as a prompt to discussion and to achieve some common agreement within the team:

"Ground rules. Really good, some may be upset, they were acceptable to all as worded"

"Good to air the ground rules, no one was shy to talk about it"

"Everyone read them, knowledge transfer. No conflict all agreed them"

"Yes a good idea with people you have not seen before."

The system was set up to flag a suggestion for a ground rule if more than half of the team members agreed that it was an important rule. However, the choice of half was arbitrary and may not be the best proportion, so an output that indicated the degree of consent to a rule might provide a better basis on which to start negotiation and make a decision on ground rules.

One team leader said that in his opinion agreeing on ground rules made no difference to his particular project team, but agreed that if ground rules were emphasised more at the beginning of the project, they would be more likely to contribute to improved performance:

"Ground rules, no difference to performance, but should be emphasised more"

A study by Patterson et al. (2005) with sports teams found some correlation between norms of social interaction and cohesion, leading to improved team performance, but no correlation between task-related norms and cohesion towards performance. This suggests a need to only use norms related to social interaction, communication, etc., rather than ground rules referring to actual work tasks. The ground rules used in this system did only refer to norms of social interaction, but related specifically to student team projects. Feedback from the students, in particular the team leaders, suggest that the function for automating the process of agreeing on ground rules was useful for these teams, notably as a basis for drawing up a contract, but also as a discussion tool and to identify expectations.

\section{Effect of Ground Rules upon Relationships in the Team}

Agreeing on ground rules and keeping to them is said to ensure that trust levels are maintained. This should enable greater levels of trust to become established in the team. The students were asked about the relationships that developed in their teams, and the feedback was interesting be- 
cause trust was not mentioned at all, but honesty and non-compliance with the agreed ground rules were mentioned as significant factors in their relationships.

There was a feeling among some student teams that agreeing on rules and signing contracts was not necessary, as honourable agreements would be sufficient to maintain team cohesion:

"Much team work is undocumented rules" TM

The feeling of one team leader was that in an effort to appear willing, answers given by team members at the beginning of the project may have been given with good intentions, but observed later behaviour may call into question the honesty of some team members. This may affect other team members' perceptions of their peers' integrity:

"Some factors have affected relationships in our team. For example honesty, not everyone contributing fairly, so need delegated tasks, no it was not fair, some people didn't see it as being honest. Need an agreement"

“...but people agree, but don't act on it. Always honest, make perfect answer” TM

But, as already noted, including ground rules in the system had some impact, either on actual relationships between the team members or by encouraging individuals to at least think about their norms:

"Set ground rules, tried to enforce them e.g. absences noted. Hard to say if it is a result [of ground rules], or made them think about expectations"

In the study by Liang, Lui, Lin, and Lin (2007) of co-located software development teams in Taiwan, differences in values held by individuals did increase relationship conflict and negatively affect team performance. In a highly structured team, agreeing on ground rules plays an important part, but the team leader or manager of the team may need to ensure the rules are being applied. Alongside ground rules, sanctions to be applied for non-compliance could also be agreed:

"The rules are a bit harsh, attendance tends to be an honourable agreement, I ask that I am informed of any non-attendance"

"During meetings in agendas. Sanction if not done. Registers monitor [attendance] and deliverables chart monitor contribution. Everyone knows where they stand. Clear what consequences were, low mark"

"All ticked everything, and did not necessarily comply"

However, if, at the beginning of a teams' project, intentions are good, it may be better if ground rules emerge over time as a need arises. What individuals say they will do and what they do in practice may differ:

"Everyone has other methods of working - develop norms after a few weeks."

"Getting members to do the work is a problem"

It was left to the discretion of the team leader what emphasis they placed upon the ground rules, and, as one team leader suggested, more emphasis on the rules from the start might have helped all members to appreciate their significance and have helped improve performance. The suggestion that the system should be cleverer, to see through dishonest answers, indicates that perhaps it should remind students of their obligations as the project progresses:

"It did not really assess what people think about, not clever enough. People can make things up"

In this case study, face-to-face communication, as well as the automated selection of ground rules, seemed to play a part in achieving some consensus between all of the team members. Mis- 
trust and miscommunication, arising from poor management of communication at a distance, may be sources of conflict in the team (Appelbaum \& Shapiro, 1998). This was echoed by respondents in this study, who said that including ground rules did get the team thinking about their means of communication and how they work with each other; indeed some team leaders reported improved team spirit, with less conflict:

"This [team spirit] is an important factor, [ground rules] help to understand how they work together and adapt to situations"

So agreeing ground rules seems to contribute to improved team spirit or cohesion. Using the ground rules suggestions as a basis for preparing a contract for all team members to sign is a means of formalising agreement to ground rules. But team leaders still had difficulties getting their team members to adhere to the rules and carry out agreed work, as good intentions at the beginning of the project dissipated. Communication throughout the project is important to constantly enforce the ground rules. However, some team leaders did report improved team spirit, which could be partially attributed to the discussion of ground rules.

\section{Usability and Affordance of the Tool}

Any system needs to be usable, for users to even attempt to use it. In addition it is difficult for the designer to envisage how students will use resources and tools for their learning activities (Conole \& Dyke, 2004). This section provides a critique of the intended and perceived affordance of the system, and an evaluation of its usability.

Overall about three quarters of the students thought that the interface was easy to use and selfexplanatory. Feedback on the prototype has, however, frequent references to the inadequate interface, which sometimes prevented the students from making full use of the system. Although results for user acceptance of the system were disappointing, team leaders pointed out that training and information at the beginning of the project would help its acceptance, so one or more sessions at the beginning of the project, explaining its functions and how to use the output would have helped:

"more awareness, needed guidance and a lecture to introduce it"

"Down to purpose and explaining the purpose - if people understand that it is there to help them" TM

"explanation on how to make use of the tool, user guidance" TM

Unfortunately, during the trial of the prototype, some team leaders did not notice the option on the screen to choose ground rules, so their team overlooked it. Some team members reported being confused about what to do with the ground rules output from the system. The system was designed with a "real (intended) affordance" of providing information, aimed at all team members, with the exception that the team leader was intended to set the system up for the team members to use. However, the "perceived affordance" of the system was at variance with the intended affordance, as students were able to choose whether or not to look at the results. It was found that team members relied on the team leader to guide them in using the system, so did not choose to look at the output themselves. Reasons given for not using the system included time constraints, which is often cited as a reason for not doing something if the tool is not immediately accessible to the user or has a time overhead to learn it. Nevertheless, just under half of the students who returned the questionnaire thought that the ground rules function was useful to them. There was also recognition that instruction for using the tool is needed at the start of the project, in order to make the most of tools on offer, as confirmed also by Dohn (2006). 
In the co-located setting, agreeing to a formal set of ground rules may be unnecessary for the smooth running of a well motivated project team, as previous experience with team working teaches team members how they should behave. But as students are working away from campus more often, this sort of informal operation may not be possible. Workman (2004) found that more formal structures were necessary for virtual teams, a result appreciated by respondents in the focus group:

"Even more difficult in virtual teams, to abide by ground rules, e.g. trust, culture develops in time." TM

In support of this, according to Wells (2002), managing cultural diversity and managing distance in virtual team working, such as when students adopt a flexible approach to managing their learning, are two challenges for the future. Similarly, setting clear roles, tasks, and ground rules for team members that are available for all the team to see may help to fulfil the expectations of individuals.

Students acknowledge that online forms of communication are also applicable for co-located students in teams, and suggest using any of a range of online tools.

"We meet together to sort the next task, face-to-face is important, if online we would need some kind of structure, communication plan, e-mail, this [system] would be more useful"

Connolly, Jones, and Jones (2007), presenting a case study of collaboration between HE and FE staff to develop online learning material, found that tension inevitably arises because of the different expectations of the participants, but suggest that addressing the issues of trust, organisation, common goals, sharing, and mutual respect may play a part in alleviating these tensions. The findings from this system trial suggest that looking at the list of ground rules prompted the students to think about their expectations, and ways in which the output from the system was used may help to promote trust, sharing and mutual respect. Overall, students recognised the potential for the ground rules function of this system, if the system is introduced at the beginning of the project and there is clearer guidance on using the system, so that all of the team members do use it.

\section{Conclusions and Future Directions}

In this paper the background to the design of a system to support agreeing on ground rules for student teams was described. The system was tested with volunteer teams using case study research, involving interviews, questionnaires, and a focus group to gather qualitative data to illustrate students' perceptions of the system in use. The outcomes are presented and evaluated in terms of team maintenance processes, such as developing team cohesion, trust, and shared understanding.

Some students did find the function for helping them to agree on ground rules useful, but the team leaders were the ones who most appreciated its usefulness. The findings confirmed that an automated process to provide suggested ground rules for a team is appropriate, but students may use the output in very different and unanticipated ways.

Team leaders were free to use the output from the system in any way they chose, but formalised contracts, based on the outputs of ground rules selected, seemed to help the teams to get started on the project and were accepted by the team members in this study. Although a formal contract signed by all of the team members does not necessarily ensure that the rules are adhered to, there was a feeling that simply looking at the ground rules encouraged the team members to think about 
their obligations, expectations of others, and working relationships, and was a benefit particularly when team members were unknown to the team leader from previous team working.

Motivation of the team members is still a potential difficulty for most team leaders, and automating the process of agreeing on ground rules may not have much impact on this. When using the system during this research, students were found to be reflecting on how they had seen tasks done by teams in the past and judging how to apply the output from the system to their team projects. This appears to be a significant contribution of the system to their soft skills development.

Although these students are studying on campus, they are working from home a lot more often, so online communication was regarded as very important. Any system intended for use with online students could be of benefit to co-located students in these circumstances, but students need to be aware of its potential to help them.

Investigating the dynamics of teamwork indicates that the team processes involved may be very complex. Automating a process for agreeing on ground rules did have some effect upon the ways in which the teams worked together, encouraging greater reflection on rules and the processes of team working. It seems that helping students through the "storming" stage might bring them to "norming" sooner. The study is to be extended to determine whether agreeing on ground rules in this way has any impact upon the performance of the student teams.

Future work to follow up on this research could include looking at the relationship between ground rules and acquiring team working skills and considering the most appropriate mix of task and social ground rules that should be incorporated into the system. As part of the learning process, team members could be asked to rate their colleagues' honesty in working in the team and commitment to the contract, as a form of peer assessment.

Providing an experience for developing team working skills is important for undergraduate students, and in this study, the system was effective in providing suggestions of ground rules for student teams to consider in different ways, as a small part of getting started on their team projects.

\section{References}

Adair, J. (1986). Effective teambuilding: How to make a winning team. London: Pan Books.

Allison, C., McKechan, D., Ruddle, A., \& Michaelson, R. (2001). A group based system for group based learning. EuroCSCL 2001, Maastricht, Netherlands.

Appelbaum, S., \& Shapiro, B. (1998). The management of multicultural group conflict. Team Performance Management, 4(5), 211-234.

Aranda, E., Aranda, L., \& Conlon, K. (1998). Teams: Structure, process, culture and politics. London: Prentice Hall.

Bales, R. (1970). Personality and interpersonal behaviour. New York: Holt, Rinehart and Winston.

Belbin, R. M. (2000). Beyond the team. Oxford: Butterworth-Heinemann.

Beranek, G., Zuser, W. \& Grechenig, T. (2005). Functional group roles in software engineering teams. Proceedings of the 2005 Workshop on Human and Social Factors of Software Engineering, St Louis, Missouri, USA, ACM.

Berge, Z. (1998). Differences in teamwork between post-secondary classrooms and the workplace. Education and Training, 40(5), 194-201.

Bion, W. (1961). Experiences in groups. London: Tavistock.

Bock, G.-W., Kankanhalli, A., \& Sharma, S. (2006). Are norms enough? The role of collaborative norms in promoting organisational knowledge seeking. European Journal of Information Systems, 15, 357-367. 
Bos, N., Olsen, J., Gergle, D., Olsen, G., \& Wright, Z. (2002). Effects of four computer-mediated communications channels on trust development. Proceedings of the SIGCHI Conference on Human Factors in Computing Systems: Changing our World, Changing Ourselves Minneapolis, USA.

Brereton, P., Lees, S., Gumbley, M., Boldyreff, C., Drummond, S., Layzell, P., Macaulay, L., \& Young, R. (1998). Distributed group working in software engineering education. Information and Software Technology, 40(4), 221-227.

Brown, R. (2000). Group processes. Oxford: Blackwell Publishers Ltd.

Burdett, J. (2003). Making groups work: University students' perceptions. International Education Journal, 4(3), 177-191.

Burdman, J. (1999). Collaborative web development: Strategies and best practices for web teams. Reading, MA: Addison Wesley.

Canterbury. (2003). Key Skills, Canterbury Christ Church University, Study-Support Unit.

Chapman, C., Ramondt, L., \& Smiley, G. (2005). Strong community, deep learning: exploring the link. Innovations in Education and Teaching International, 42(3), 217-230.

Connolly, M., Jones, C., \& Jones, N. (2007). Managing collaboration across further and higher education: A case in practice. Journal of Further and Higher Education, 31(2), 159-169.

Conole, G., \& Dyke, M. (2004). What are the affordances of information and communication technologies? ALT-J: Research in Learning Technology, 12(2), 113-124.

Cooper, G., \& Heinze, A. (2003). Centralisation of assessment: Meeting the challenges of multi-year team projects in information systems education. Journal of Systems Education, 18(3), 345-356.

Dohn, N. B. (2006). Affordances - A Merleau-Pontian account. Proceedings of the Fifth International. Conference on Networked Learning, Lancaster University.

Driskell, J., Goodwin, G., Salas, E., \& O'Shea, P. (2006). What makes a good team player? Personality and team effectiveness. Group Dynamics: Theory, Research and Practice, 10(4), 249-271.

Dunne, E., \& Rawlins, M. (2000). Bridging the gap between industry and higher education: Training academics to promote student teamwork. Innovations in Education and Teaching International, 37(4), 361-371.

Edwards, M., \& Clear, F. (2001). Supporting the collaborative learning of practical skills with computermediated communications technology. Educational Technology and Society, 4(1), 80-92.

Felder, R., \& Brent, R. (1994). Cooperative learning in technical courses: Procedures, pitfalls, and payoffs. North Carolina State University. Retrieved from http://www.ncsu.edu/felderpublic/Papers/Coopreport.html,

Fellers, J. (1996). Teaching teamwork: Exploring the use of cooperative learning teams in information systems education. The DATABASE for Advances in Information Systems, 27(2), 44-60.

Ford, M., \& Morice, J. (2003). Using micro management techniques to overcome problems in group assignments. Proceedings of InSITE, Informing Science and IT Education, Pori, Finland. Retrieved from http://proceedings.informingscience.org/IS2003Proceedings/docs/161Ford.pdf

Garratt, B. (1994). The learning organization. London: Harper Collins.

Gatlin-Watts, R., Carson, M., Horton, J., Maxwell, L., \& Maltby, N. (2007). A guide to virtual teaming. Team Performance Management, 13(1/2), 47-52.

Golembiewski, R. T., \& McConkie, M. (1975). The centrality of interpersonal trust in group processes. In C. L. Cooper (Ed.), Theories of Group Processes. London: Wiley.

Griffiths, S., \& Partington, P. (1992). Enabling active learning in small groups. Sheffield: CVCP.

Groesbeck, R., \& Van Aken, E. (2001). Enabling team wellness: Monitoring and maintaining teams after start-up. Team Performance Management, 7(1/2), 11-20. 
Hansen, R. (2006). Benefits and problems with student teams: Suggestions for improving team projects. Journal of Education for Business, 82(1), 11-19.

Hartley, P. (1997). Group communication. London: Routledge.

Hordyk, V. (2007). A convergence of perspectives: Enhancing students' employability. Proceedings of the 5 th Education in a Changing Environment Conference, Salford, UK.

Johnson, D., \& Johnson, F. (1997). Joining together: Group theory and group skills. Needham Heights: Allyn \& Bacon.

Johnson, D. W., Johnson, R. T., \& Smith, K. A. (1991). Cooperative learning: Increasing college faculty instructional productivity. School of Education and Human Development, George Washington University.

Lakkala, M., Lallimo, J., \& Hakkarainen, K. (2005). Teachers' pedagogical designs for technologysupported collective inquiry: A national case study. Computers \& Education, 45(3), 337-356.

Lehtinen, E., Hakkarainen, K., Lipponen, L., Rahikainen, M., \& Muukkonen, H. (2002). Computer supported collaborative learning: A review. CLNet. Retrieved from http://citeseerx.ist.psu.edu/viewdoc/download?doi=10.1.1.109.5052\&rep=rep1\&type=pdf,

Liang, T.-P., Lui, C.-C., Lin, T.-M., \& Lin, B. (2007). Effect of team diversity on software project performance. Industrial Management and Data Systems, 107(5), 636-653.

Livingstone, D., \& Lynch, K. (2000). Group project work and student-centred active learning: Two different experiences. Studies in Higher Education, 25(3), 325-345.

McAlister, D. (2006). The project management plan: Improving team process and performance. Marketing Education Review, 16(1), 97-103.

Mennin, S. (2007). Small-group problem based learning as a complex adaptive system. Teaching and Teacher Education, 23, 303-313.

Newell, S., David, G., \& Chanel, D. (2007). Exploring trust among globally distributed work teams. 40th Annual Hawaii International Conference on Systems Sciences, Hawaii, IEEE.

Patterson, M., Carron, A., \& Loughead, T. (2005). The influence of team norms on the cohesion-selfreported performance relationship: A multi-level analysis. Psychology of Sport and Exercise, 6, 479493.

Powell, A., Piccoli, G., \& Ives, B. (2004). Virtual teams: A review of current literature and directions for future research. The DATABASE for Advances in Information Systems, 35(1), 6-36.

Prichard, J., Stratford, R., \& Bizo, L. (2006). Team-skills training enhances collaborative learning. Learning and Instruction, 16, 256-265.

Ruel, G., \& Bastiaans, N. (2003). Free-riding and team performance in project education. The International Journal of Management Education, 3(1), 26-37.

Syer, J., \& Connolly, C. (1996). How teamwork works: The dynamics of effective team development. London: McGraw-Hill.

Tuckman, B. W. (1965). Developmental sequence in small groups. Psychological Bulletin, 63, 384-399.

Wells, C. (2002). Teaching teamwork in information systems. In E. Cohen (Ed.), Challenges of information technology education in the 21 st century (pp. 1-24). London: Idea Group.

Whatley, J., Staniford, G., Beer, M., \& Scown, P. (1999). Intelligent agents to support students working in groups online. Journal of Interactive Learning Research, 10(3/4), 361-373.

Workman, M. (2004). Goals, relationships, information and processes in global virtual team performance. International Journal of Management and Decision Making, 5(4), 348-372.

Zaccaro, S., Rittman, A., \& Marks, M. (2002). Team leadership. The Leadership Quarterly, 12, 451-483. 


\section{Biography}

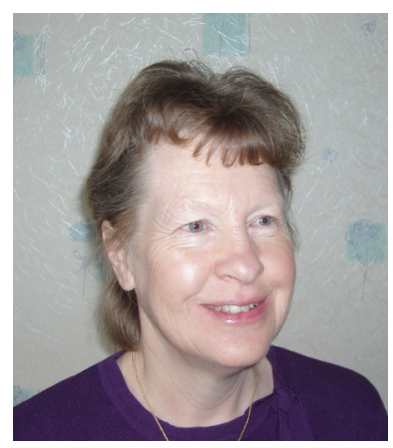

Janice Whatley is a lecturer in Salford Business School at the University of Salford. Her research interests are concerned with improving teaching and learning for students in higher education, and developing IT skills. Janice is also interested in encouraging collaboration between students, having recently co-ordinated the European funded CAB Project, to enable students to learn through collaborating online with students from other European countries. Teaching subjects include multimedia development, e-learning and using Information Technology in business. 